\section{Nuestro cine y nuestra literatura Amores equívocos}

Jorge Eslava $\bigwedge_{\text {ción de cuerpos con el cine pe- }}^{\text {antengo una saludable separa- }}$ ruano de las últimas décadas. Nos reencontramos solo ocasionalmente y nos bastan, para pasar un rato inquietante, una butaca y unos sorbos de agua mineral. Acudo solitario a estas citas, arrastrando el ánimo, pero armado de ilusión por algún comentario entusiasta o benévolo que he leído. No tarda en saltarme a los ojos el chasco de la ignominia.

No mencionaré aquellas películas - la lista es larga y el lector agudo-, que obligan a los actores a repetir guiones mal escritos. Los encuadres, el pulso narrativo y la caracterización de los personajes brillan como una cerilla en la noche espacial. Está claro que quien escribe esta nota es, en materia cinematográfica, un pobre diablo: jamás ha escrito un guión ni dirigido una película. Solo lo ampara la devoción por el cine y la literatura.

Porque ensimismarse ante la pantalla o las páginas de un libro son gestos equivalentes de cultura. Pequeños y libres que nos hacen crecer humanamente. Ha cumplido más de cien años la discusión —nunca inútil- de comparar las quimeras del alfabeto con los ilusionismos de la pantalla. Controversia que a menudo enturbia el entendimiento con preguntas sobre las relaciones competitivas y peligrosas que guardan entre sí. Prefiero pensar en el cine y la literatura como dos amantes 
que se enriquecen, más por sus diferencias que por sus semejanzas.

Al carácter aislado y apacible de la escritura (por tortuosa que sea), cuyo texto literario termina ofreciéndose al lector como un juego dialéctico, se opone la complejidad y el gregarismo del rodaje fílmico y de la edición, además de las condiciones impositivas de la imagen. El lector y el espectador disfrutan o se conmueven en sus asientos reales, porque escapan de la precariedad que amenaza sus vidas e ingresan a una zona crepuscular donde algo extiende o ahonda su experiencia. Las vías han sido distintas, aunque hayan gravitado en una dimensión desconocida con la misma intensidad.

No es motivo ahora de cuestionar, por ejemplo, si la imagen de escritor que crea Nicholson en El resplandor es una afrenta para el gremio o si la novela de Thomas Mann, Muerte en Venecia, es inferior a la cinta de Luchino Visconti. Tampoco cuán abundantes son las películas inspiradas en fuentes literarias, con mayor frecuencia en novelas y piezas dramáticas, sin que lo advierta el espectador. Ni de llamar la atención sobre las notables películas nacidas de alguna mediocre novela, que son tantas. Un caso excepcional es El tercer hombre, basada en una novela de Graham Greene.

Aunque me gustaría detenerme en las tentativas del cine por construir la figura del escritor, que han corrido di- versas suertes. Entre mis preferidas están Días sin buella, un clásico de Wilder, que ofrece con acrimonia el retrato de un novelista fracasado y alcohólico, y la película de Wayne Wang, Cigarros, con un entrañable William Hurt. $\mathrm{Al}$ extremo opuesto, El lado oscuro del corazón no tiene competencia. Me parece una cinta infame y que sin embargo obtuvo premios y hasta tuvo una segunda entrega. Le corresponde a su director el ominoso privilegio de haber confundido un poeta con una golosina.

En nuestro medio hubo también un cortometraje sobre César Vallejo, con un actor impasible que se movía posando ante la cámara — procurando imitar la célebre foto del puño y el bastón- y hablando en el tono grave de "hay golpes en la vida". Fue tan agraviante a su memoria como los intentos de hace algunos años por expatriar sus restos. Y he llegado con este recuerdo al propósito inicial de las líneas que escribo: con qué textos o motivos de nuestra literatura podrían ensayarse algunas pruebas cinematográficas.

Consideremos como referencia $L a$ ciudad y los perros. De esta admirable novela de Vargas Llosa, un impetuoso Lombardi salió muy bien librado. De un modelo narrativo complejo, la arista que abordó la película y el guión de José Watanabe fueron de primera línea. La cámara se desplazó con audacia, el ritmo dramático no desaceleró y los actores — casi todos debutantes_ pusieron tal 
sinceridad y nervio que le dieron consistencia y credibilidad a esta versión cinematográfica que cumple 22 años. Desde entonces hasta ahora creo que se ha retrocedido; por ejemplo, Ciudad de $M$ es una intentona bien maleada de la novela de Óscar Malca Al final de la calle. Yo he crecido en Magdalena, cerca del famoso "Fuerte Apache" y nunca vi tipos parecidos a Magill ni a Mayer.

Aunque no se trata de una novela, de este juicio último se libra Días de Santiago. Nos dio una mirada honesta y áspera de la secuela que dejó en un sector de nuestros compatriotas la violencia política. El guión no apeló, como suele ocurrir, a esa sucesión interminable de palabrotas para dar con el tono coloquial. Sólido y selectivo, supo el lenguaje representar convincentemente el discurso popular. Y la actuación de Pietro Sibille fue impecable.

Creo que a muchos lectores nos gustaría ver una película sobre la vida del poeta Carlos Oquendo de Amat, cuyo único libro es un homenaje al cine. En Cinco metros de poemas, con sus diez minutos de intermedio, Oquendo nos recrea la época de la vanguardia literaria y política que vivió el Perú en los años veinte del siglo pasado. El tránsito vital del poeta —enfermo, perseguido, deportado- y su muerte legendaria en la sierra de Navacerrada, poco antes de que estos campos fueran bombardeados por los fascistas de la Guerra Civil Española. Vargas Llosa gestó un mito sobre "la camisa roja" que vistió el poeta, antes de morir, como símbolo de su pasión por la poesía.

$\mathrm{Al}$ año siguiente de la publicación de los Cinco metros de poemas, aparece una genialidad inclasificable: $L a c a$ sa de cartón (1928), de Martín Adán. Relato poemático escrito con el desenfado de un adolescente sabihondo y burlón. Relato introspectivo, pleno de imágenes delirantes y apuntes mordaces de las costumbres del balneario aristocrático y decadente que era entonces Barranco. Le vendría estupendamente, si se tratara de un mediometraje, acompañarlo de la nouvelle de José Diez-Canseco titulada El Gaviota (1929-1930). Imagen de esos mismos años, pero desde la perspectiva de un chico del puerto del Callao. Una mirada y un lenguaje arrabaleros, con las preocupaciones por fundar relaciones familiares ausentes. Ambos relatos son, en gran medida, complementarios.

Con algunos cuentos de Julio Ramón Ribeyro se han realizado cortos. Sin embargo no se ha prestado atención a sus novelas: la magnífica Crónica de San Gabriel y Los geniecillos dominicales. La primera fue publicada en 1960 y es un doble testimonio de un adolescente urbano: la ardua formación del amor hacia su prima Leticia - la presencia femenina más perturbadora de la literatura peruana- y la constatación de una irremisible degradación de la casta provinciana a la que él está emparentado. Un extraordinario cuadro de desmoronamiento individual y social. 
Los geniecillos dominicales (1965) parece más una sarta de cuentos, al estilo de la picaresca española, que una novela orgánica. Es una historia ágil y disparatada de un grupo de jóvenes limeños, cuyo protagonista Ludo Tótem ansía convertirse en escritor, pero no hace más que entrar en una vertiginosa espiral de indigencia, juergas y relaciones peligrosas que lo conducen hasta el asesinato. Un paseo trepidante por la geografía caótica de Lima y por los baches de la conciencia juvenil, ante la pulverización (constante ribeyriana) de los modales aristocráticos. Un largometraje con esta novela no tendría pierde.

Aunque más joven que Ribeyro, Vargas Llosa pertenece a la misma promoción de ilustres intelectuales y escritores peruanos. La llamada Generación del Cincuenta reúne una cantidad considerable de narradores cuyas historias ofrecen calas interesantes en nuestra realidad. El caso de Vargas Llosa es excepcional, pues varias de sus obras han sido llevadas al cine: La ciudad y los perros, Los cachorros, La tía Julia y el escribidor y Pantaleón y las visitadoras. Ignoro si alguna más, pero salvo la primera las demás son irrelevantes.

Considero que intentar una película con Los jefes, cuento de su primerísima producción, constituiría un esfuerzo plausible. La historia narra una revuelta escolar en un colegio nacional, donde los estudiantes se rebelan ante unas medidas autoritarias y arbitrarias de la dirección del plantel. Una situación, además, autobiográfica de nuestro más renombrado narrador. Frente a tanta rebeldía sin brújula que vemos hoy, el drama de este cuento enfrenta hondos conflictos de poder no solo entre alumnos y profesores, sino además entre los propios adolescentes que persiguen un liderazgo entre pares. Los códigos machistas y la brutalidad contenida, en el marco de las jerarquías institucionales, ponen en escena elementos explosivos para una cinta de buen calibre. Sería, de paso, una necesaria llamada de atención para los mentores de nuestro Ministerio de Educación.

También pertenecientes a la Generación del Cincuenta, Edgardo Rivera Martínez y Antonio Gálvez Ronceros indagan con gran talento en nuestra realidad, aunque enfocados respectivamente en el mundo andino y de la negrería del sur chico. En el volumen $A ́ n$ gel de Ocongate (1986) de Rivera Martínez hay cuentos notables —en especial el que da título al libro-, que respiran el drama de la identidad o "ajenidad" nacional, bajo un mundo mágico de cosmogonía andina. Gálvez Ronceros publicó hace treinta años un libro de una enjundia y sabrosura insuperables: $\mathrm{MO}$ nólogo desde las tinieblas (1975). Son breves estampas de la vida de la campiña, en El Guayabo y otras comunidades negras, que nos enseñan de la vida gozosa y las penas que experimentan de sol a sol nuestros hermanos negros. 
En la línea de la denominada literatura de formación, es decir aquellos textos que asisten a los rituales del crecimiento de un adolescente y que someten al sujeto a pruebas múltiples: relación con sus padres, búsqueda de pareja, conflictos con su cuerpo, confusión sobre el futuro... tenemos libros importantes: Huerto cerrado (1968), el primer conjunto de cuentos de Bryce Echenique, en el que el protagonista Manolo - evidente alter ego del autorcubre un periplo de unos diez años y se ve enfrentado a vicisitudes entre dolorosas y divertidas. Un ambiente sombrío y de recogimiento espiritual es el que nos ofrece Miguel Gutiérrez en su novela El viejo saurio se retira (1969) recientemente reeditada-, que narra las experiencias de un grupo de muchachos en un ortodoxo colegio religioso. Una mirada más bien brutal e hipersensible es la de Urteaga Cabrera, en su estremecedora novela Hijos del orden. También sobre modelos represores de educación, pero esta vez en un centro de rehabilitación para chicos. Por el contrario, expansiva y solar, siempre adolescente, es el libro de cuentos de Fernando Ampuero bajo un título bien stone: Deliremos juntos (1974). Creo que no hay un acercamiento más desenfadado — con aires de marihuana y rock- de la juventud clasemediera de los setenta.

Me excuso, pues estoy excediéndome del espacio ofrecido. Solo algunas referencias más. Arrancando la década del ochenta nos encontramos con dos relatos que podrían ser de gran interés para nuestros realizadores: La ópera de los fantasmas (1980), de Jorge Salazar, sobre la penosa tragedia del Estadio Nacional donde perecieron más de trescientas personas, a causa de una infausta intervención de la policía. Al año siguiente, Cromwel Jara asestó un recto a la mandíbula de los lectores con Montacerdos, una incursión en la denigrada existencia humana en las barriadas limeñas. De los noventa solo mencionaré la singular nouvelle La conciencia del límite último (1990), un policial intimista y complejo de Carlos Calderón Fajardo, y la novela de tesis de Carlos Herrera, Blanco y negro (1995), que es una inmersión existencial en las leyes opuestas de la razón y del deseo. Ambas son juegos inteligentes de ajedrez, con las que podría conseguirse interesantes películas.

Sin duda quedan muchas obras sin mención en esta relación arbitraria y bien intencionada, que espero sea de provecho para nuestros cineastas y los motive a revisarlas. Creo, por último, que la nueva promoción de creadores - fraguados en el cine, la música, el periodismo- podrían asumir con calidad el oficio de guionistas. Nombres como Gastón Agurto, Diego Otero, Kike Planas, Jeremías Gamboa, Sergio Galarza... han demostrado poseer esa cualidad hipnótica que reclama el buen cine. 